\title{
Corrigendum: Biochemistry and genetics of ACC deaminase: a weapon to "stress ethylene" produced in plants
}

\author{
Rajnish P. Singh ${ }^{1}$, Ganesh M. Shelke ${ }^{2}$, Anil Kumar ${ }^{2}$ and Prabhat N. Jha ${ }^{1 *}$ \\ ${ }^{1}$ Department of Biological Sciences, Birla Institute of Technology and Science (BITS) Pilani, Pilani, India, ${ }^{2}$ Department of \\ Chemistry, Birla Institute of Technology and Science (BITS) Pilani, Pilani, India
}

Keywords: ACC, Acds, ethylene, abiotic stress, PGPR

\section{A corrigendum on}

Biochemistry and genetics of ACC deaminase: a weapon to "stress ethylene" produced in plants by Singh, R. P., Shelke, G. M., Kumar, A., and Jha, P. N. (2015). Front. Microbiol. 6:937. doi: 10.3389/fmicb.2015.00937

\section{OPEN ACCESS}

Edited and reviewed by: Ying $\mathrm{Ma}$,

University of Coimbra, Portugal

${ }^{*}$ Correspondence:

Prabhat N. Jha

prabhatn.jha@gmail.com

Specialty section

This article was submitted to

Plant Biotic Interactions,

a section of the journal

Frontiers in Microbiology

Received: 07 October 2015 Accepted: 28 October 2015 Published: 06 November 2015

Citation:

Singh RP, Shelke GM, Kumar $A$ and Jha PN (2015) Corrigendum: Biochemistry and genetics of ACC deaminase: a weapon to "stress

ethylene" produced in plants.

Front. Microbiol. 6:1255.

doi: 10.3389/fmicb.2015.01255
We mistakenly did not cite the reference Gontia-Mishra et al. (2014) in the text. Please find the following corrected paragraph with the given citation in the appropriate place. The full citation is also written below for inclusion in the reference list.

As reviewed in Gontia-Mishra et al. (2014), among eukaryotes, production of ACCD is well evident in some fungi, which include a few species of yeast such as Hansenula saturnus (Minami et al., 1998), Issatchenkia occidentalis (Palmer et al., 2007), other fungal species namely Penicillium citrinum and Trichoderma asperellum, and a stramnopile, Phytophthora sojae (Jia et al., 1999; Viterbo et al., 2010; Singh and Kashyap, 2012). Recently, ACCD activity has also been observed in certain plants such as Arabidopsis thaliana, poplar, and tomato plant (McDonnell et al., 2009; Plett et al., 2009).

\section{REFERENCES}

Gontia-Mishra, I., Sasidharan, S., and Tiwari, S. (2014). Recent developments in use of 1-aminocyclopropane-1- carboxylate (ACC) deaminase for conferring tolerance to biotic and abiotic stress. Biotechnol. Lett. 36, 889-898. doi: 10.1007/s10529014-1458-9

Jia, Y. J., Kakuta, Y., Sugawara, M., Igarashi, T., Oki, N., Kisaki, M., et al. (1999). Synthesis and degradation of 1-aminocyclopropane-1-carboxylic caid by Penicillium citrinum. Biosci. Biotechnol. Biochem. 63, 542-549. doi: 10.1271/bbb.63.542

McDonnell, L., Plett, J. M., Andersson-Gunnerås, S., Kozela, C., Dugardeyn, J., Van Der, S. D., et al. (2009). Ethylene levels are regulated by a plant encoded 1-aminocyclopropane-1-carboxylic acid deaminase. Physiol. Plant. 136, 94-109. doi: 10.1111/j.1399-3054.2009.01208.x

Minami, R., Uchiyama, K., Murakami, T., Kawai, J., Mikami, K., Yamada, T., et al. (1998). Properties, sequence, and synthesis in Escherichia coli of 1- aminocyclopropane-1-carboxylate deaminase from Hansenula saturnus. J. Biochem. $123,1112-1118$. 
Palmer, C., Golden, K., Danniels, L., and Ahmad, H. (2007). ACC deaminase from Issatchenkia occidentalis. J. Biol. Sci. 7, 188-193. doi: 10.3923/jbs.2007. 188.193

Plett, J. M., McDonnell, L., and Regan, S. (2009). Plant encoded 1aminocyclopropane-1-carboxylic acid deaminase activity implicated in different aspects of plant development. Plant Signal. Behav. 4, 1186-1189. doi: 10.4161/psb.4.12.10060

Singh, N., and Kashyap, S. (2012). In-silico identification and characterization of 1-aminocyclopropane-1-carboxylate deaminase from Phytophthora sojae. J. Mol. Model. 18, 4101-4111. doi: 10.1007/s00894-0121389-0

Viterbo, A., Landau, U., Kim, S., Chernin, L., and Chet, I. (2010). Characterization of ACC deaminase from the biocontrol and plant growth-promoting agent
Trichoderma asperellum T203. FEMS Microbiol. Lett. 305, 42-48. doi: 10.1111/j.1574-6968.2010.01910.x

Conflict of Interest Statement: The authors declare that the research was conducted in the absence of any commercial or financial relationships that could be construed as a potential conflict of interest.

Copyright (c) 2015 Singh, Shelke, Kumar and Jha. This is an open-access article distributed under the terms of the Creative Commons Attribution License (CC BY). The use, distribution or reproduction in other forums is permitted, provided the original author(s) or licensor are credited and that the original publication in this journal is cited, in accordance with accepted academic practice. No use, distribution or reproduction is permitted which does not comply with these terms. 